\title{
Erratum to: Mind the Gap: Appropriate Evolutionary Perspectives Toward the Integration of the Sciences and Humanities
}

\author{
Leslie L. Heywood • Justin R. Garcia • David Sloan Wilson
}

Published online: 10 April 2010

(C) Springer Science+Business Media B.V. 2010

\section{Erratum to: Sci \& Educ DOI 10.1007/s11191-009-9193-7}

Portions of the wording in the paragraph starting with "Though not specifically from a perspective of cultural evolution" (Section 5, "Applications of Evolution to Literature: Integrative Perspectives") is misquoted. The correct quoted passage should read:

Only an adaptationist paradigm can address two important and incontrovertible facts about the implied subject of humanistic study-humanity. First, all people who have lived during the past 250 thousand years have been members of one species and, like other species, share a common nature-human nature. Comprehending this fact is essential for contemporary understanding of world art, as of world history, religion, health, education, or any other human subject. Second, the human mind and the behaviors and artifacts it produces are biologically-based-that is, the result of the electrochemistry and anatomical structure of the brain that has evolved like other parts of the body to help individuals survive and reproduce. Because all individuals have similar emotional needs and motivational structures, it is obsolete and limiting to treat human behavior as being only culturally or individually constructed. (Dissanayake 2008, pp. 23-24)

The online version of the original article can be found under doi:10.1007/s11191-009-9193-7.

\section{L. Heywood}

Department of English, and Institute for Evolutionary Studies, Binghamton University, Binghamton, NY 13902-6000, USA

e-mail: heywood@binghamton.edu

J. R. Garcia $(\bowtie)$

Departments of Anthropology and Biological Sciences, and Institute for Evolutionary Studies, Binghamton University, Binghamton, NY 13902-6000, USA

e-mail: justin.r.garcia@gmail.com

\section{S. Wilson}

Departments of Biological Sciences and Anthropology, and Institute for Evolutionary Studies, Binghamton University, Binghamton, NY 13902-6000, USA

e-mail: dwilson@binghamton.edu 